\title{
Corn harvester cutting machine overall structure and working principle
}

\author{
Song Xiangwen ${ }^{1, a}$, Cao Shukun ${ }^{2 *, b}\left(\right.$ Corresponding author), Wang Chong ${ }^{3, c}$
}

\author{
Wang Heng 4 ,d \\ ${ }^{1}$ Nanxinzhuang West Road 336Jinnan, School of Mechanical Engineering, University of Jinan, \\ Jinan 250022, Shandong Province, China \\ ${ }^{2}$ Nanxinzhuang West Road 336Jinnan, School of Mechanical Engineering, University of Jinan, \\ Jinan 250022, Shandong Province, China \\ ${ }^{3}$ Nanxinzhuang West Road 336Jinnan, School of Mechanical Engineering, University of Jinan, \\ Jinan 250022, Shandong Province, China \\ ${ }^{4}$ Nanxinzhuang West Road 336Jinnan, School of Mechanical Engineering, University of Jinan, \\ Jinan 250022, Shandong Province, China \\ a751937831@qq.com b87756997@qq.com c535756212@qq.com d1292553067@qq.com
}

Keywords:9-line; Horizontal picking the head roller horizontal pick roller; Spacing adjustable; Cutting machine folding

Abstract.Nowadays, the corn harvester has a variety of forms, including horizontal, vertical, and combinational pick roller, etc. New maize Corn harvester with 9-line designed in this paper, the header using the horizontal pick roller. In this paper, cutting machine is designed for spacing can be adjusted, cut folding machine, the structure of the whole machine will have a big change, for this machine with large 9-line, is a new breakthrough on the structure.

\section{The research background and significance}

During the structure design of corn harvester, we need to analyze the existing structure, find the problems existing in the nowadays corn harvester, put forward the ideas of reasonable, give the new design concept, and design effective and feasible on the basis of existing corn harvester technology. Traditional corn harvester spacing is set in the beginning, the design of the removable ear roller group and the distance between the front guard board more wide cutting length is more wide, so a lot of corn harvester opened the front end of the Angle as far as possible big in order to get a bigger cut of will spike roller guard, if the cutting machine do nine lines, and to ensure the cutting length is big enough, the traditional design are bulky, and 9 line width is large, the header isn't very convenient for transportation and walking.

\section{The overall structure design of cutting machine}

This paper designed a new type of corn harvester cutting machine is mainly composed of mowing machine racks, folding mechanism, 9 groups pick roller combination, guide rail, slider, twisted dragon, guide rail support frame, hydraulic cylinder and guard plate, guide was in guide supporting frame, 9 pick spike roller group placed on the guide rail, between each two groups to pick a spike roller installed a hydraulic cylinder, cutting platform supporting frame is divided into three parts, through folding mechanism connection, folding mechanism by hydraulic cylinder and 
brace connection the middle, twisted dragon is divided into three sections, each section of the corresponding part of the mowing machine. Guide rail support frame is divided into three parts that are left, and right of parallel but not collinear, on each distribution respectively two groups to pick a spike roller combination, distribution among 5 pick spike roller group, the left side pick spike roller combination is connected to the extreme left of the left guide rail brace, drive to the left side when sliding guide rail brace sliding together, make the left guide rail brace can receive the inner side of the middle part, the right guide rail brace is also, all can receive the inner side of the middle part, the concrete structure as shown in Fig 1.1.Cutting machine set has a set of removable ear offset hydraulic cylinder roller group, 9 groups pick ears can roll in the hydraulic cylinder drive at the same time to move to cut the table side.

Each group was picked a spike roller powered by a hydraulic motor, at the same time, the power of ground dragon is provided by hydraulic motor , the corn cutting machine is designed to become a folding structure, to meet the design of this structure in the process of the folding, non-interference in each other the parts cut corn machine, folding structure as shown in Fig1.2.

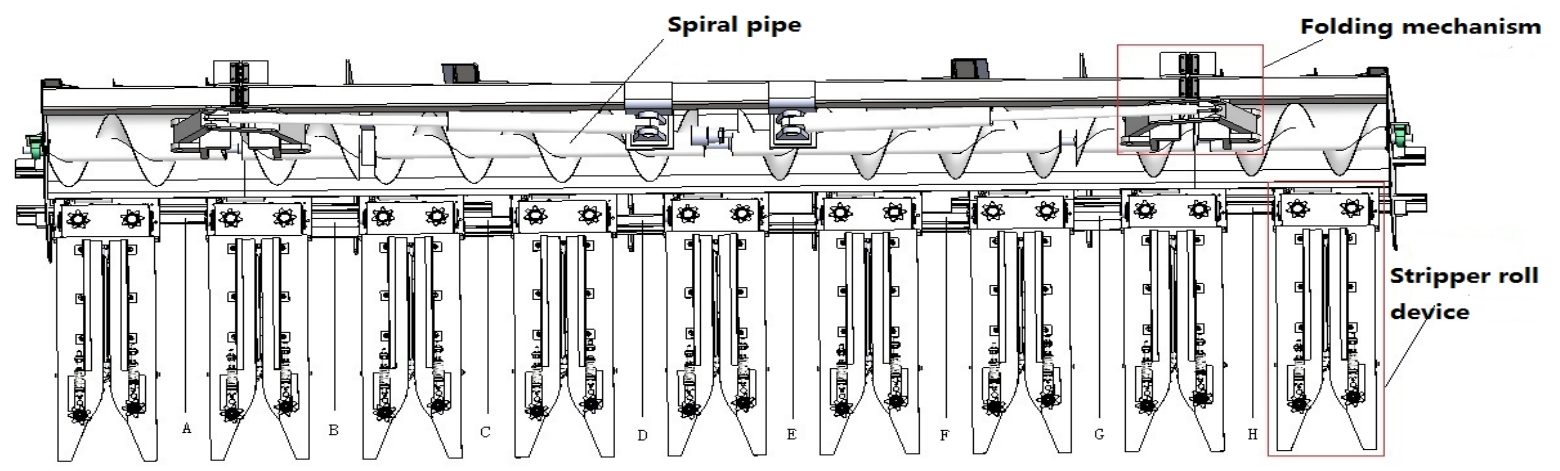

Fig. 1.1 overall structure of cutting table 
Due to the large width 9-line cutting machine, cutting machine was designed for folding form, the total width of $4550 \mathrm{~mm}$ of the column, the two sides of the folding part is $860 \mathrm{~mm}$, the width of the folding function by two telescopic hydraulic cylinder, folding structure designed was ingeniously simple, low cost, convenient and practical, and can avoid in the process of cutting machine folding dead point position. Making the process is more smoothly, after folding effect as shown in Fig 1.3. Heave the rotation of the dragon by is located in the motor of the middle part via chain wheel drive adjustment, heaving the dragon as a result of the need of folding also do the structure design of the section, and design a reasonable joint structure, in both sides of the cut sets are in a folding state, intermediate section cutting machine also can harvest.

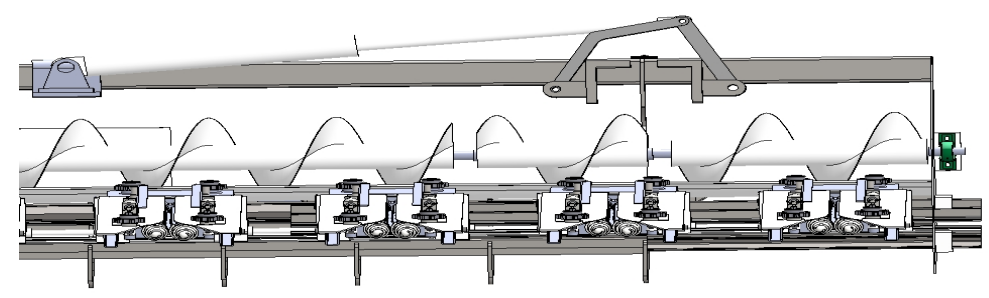

Fig1.2 cutting platform folding structure

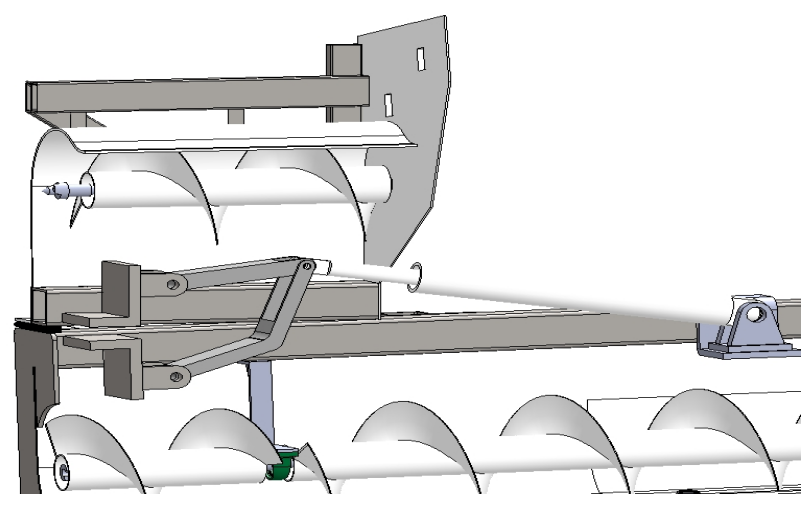

Fig 1.3 cut fold after rendering

Each group of picking the head roller includes two pick roller, the ear roll armor plate and the roller gear box, pick the spike roller combination structure as shown in Fig 1.4, left picture for the processing of assembly has finished picking roller combination physical diagram. Each pick spike roller combination connection below 4 sliders, placed in the guide of the racks are laid on the slider ,the guide choses Taiwan CSK LMG30H, width of guide rail is $28 \mathrm{~mm}$, width of slider is 60 $\mathrm{mm}$, each group pick about $800 \mathrm{n}$, the gravity of the spike roller combination average assigned to four slide blocks, each slide block under gravity is $200 \mathrm{n}$, far less than the maximum of slider bearing $50 \mathrm{kn}$, fully meet the requirement of the stress of the slider. Slider connection guide rail are placed in the guide rail support frame, 9 groups to pick a spike roller combinations in the guide support frame assembly object as shown in Fig 1.5. 

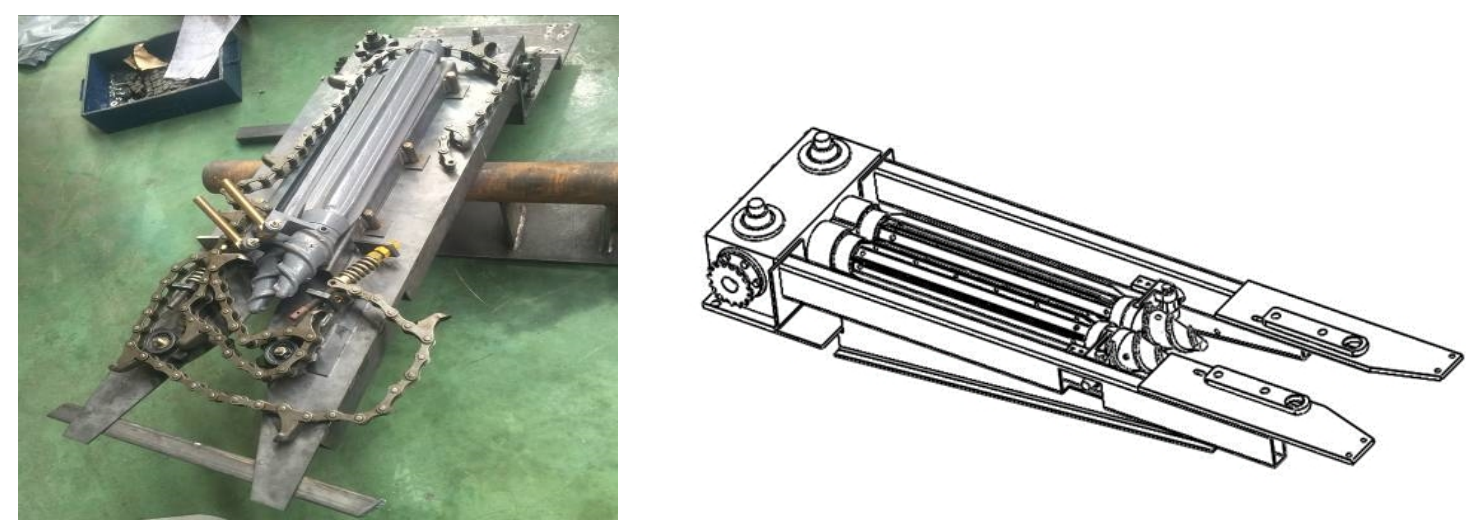

(a)pick roller combination physical diagram (b) three-dimensional figure of the picking spike roller combination

Fig 1.4 pick roller combination

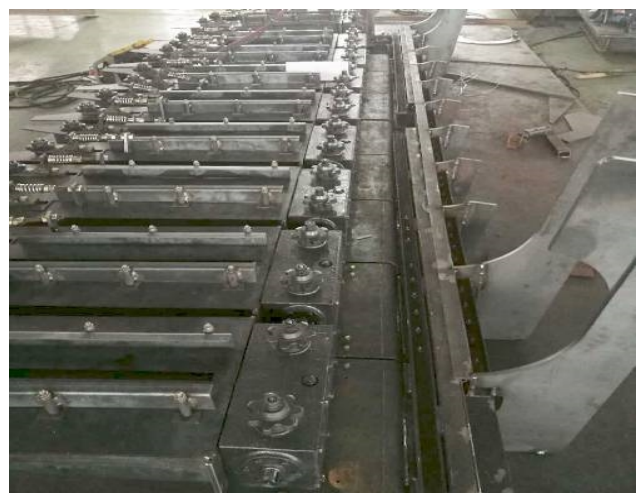

Fig 1.59 pick spike roller group assembly object

Traditional way of cutting machine transmission has not applied to this design, the driving way of cutting machine on the market generally starts passed to all cutting machine side gear box, each gear box drive the corresponding spike roller rotation, due to pick a spike roller combination is around here can adjust spacing, so you need to change the traditional mode of transmission, each group sticks to install a provide pick spike roller rotation and chain rotation of motor is designed, the motor connection a sprocket, power through the chain transfer to the gearbox, gearbox and drive the two rolls to the inside of the turn.

\section{Cutting machine working principle}

The design is different from the traditional design of the corn, the new design will be cut table 9 groups to pick a spike roller modular, made into 9 groups to pick a spike roller combination, connection between every two combinations a hydraulic cylinder make removable ear between two rollers can move around within the scope of the hydraulic cylinder stroke. Then they will spike roller combination one lined on the guide rail, guide rail bottom laid in the guide support frame. On the harvesting machine arrived at the work site, machines were parked at the side of the harvest area, the cutting table placed cameras started to collect pictures of corn plant, field collected photos on PC image preprocessing, and determine the corn plant location. After PC calculated the field planting corn planting distance through processing, will pass the final distance value to the PLC, 
PLC controller controlled the cut sets of hydraulic valves to open and close to control cutting machine for folding action, adjusted the offset space action and action. After adjusting well spacing, machine can open the motor, hydraulic motor through a gearbox to drive to pick a spike at the end of the roll and chain is designed, start the harvester to harvest work.

\section{The key on structural design of the cutting machine}

\section{pick a spike roller support plate and ground docking}

The role of the combined support plate of the stripper roll is to support the combinati on of 9 sets of stripper rolls, and to facilitate the connection of the stripper roll assembly and the guide rail。In order to have higher strength and stability, The upper surface of the left side of the supporting plate is connected with a pair of slide blocks, and the lower sur face of the right side is connected with a pair of slide blocks, Thus, the sliding block can always bear the pressure action caused by the combination of the stripper rolls, Not subject to upward pull, Fully guarantee the life of the slider, The actual figure of the stripper sup port plate is shown in Fig 2.1 The support plate design is simple, but for the header row spacing adjustable plays a very important role.

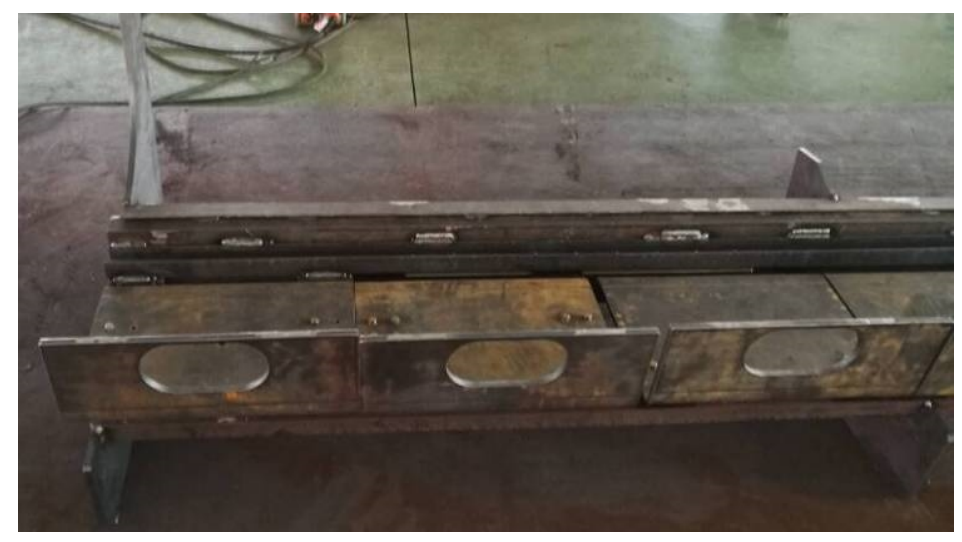

Fig 2.1. Pick spike roller support plate material object diagram

In the folding process, the dragon is also done with cutting platform fold open design, it through a special connection structure, concrete structure as shown in Fig 2.2, to ensure the stranded when all cut sets of the dragon can work normally, also be convenient to fold at the same time, the concrete structure as shown in figure, heave of the dragon a diameter of $121 \mathrm{~mm}$, thickness is $5 \mathrm{~mm}$, with a bearing seat to support the middle section of ground dragon, using two around each bearing to support, strong stability. This special connection structure in docking female head of the built-in spring core, ensure the ground dragon rotated to any Angle for docking will not produce rigid collision, docking male head part to make a conical structure, fully guarantee ground can be in the middle of both side of the dragon and the smooth docking. 


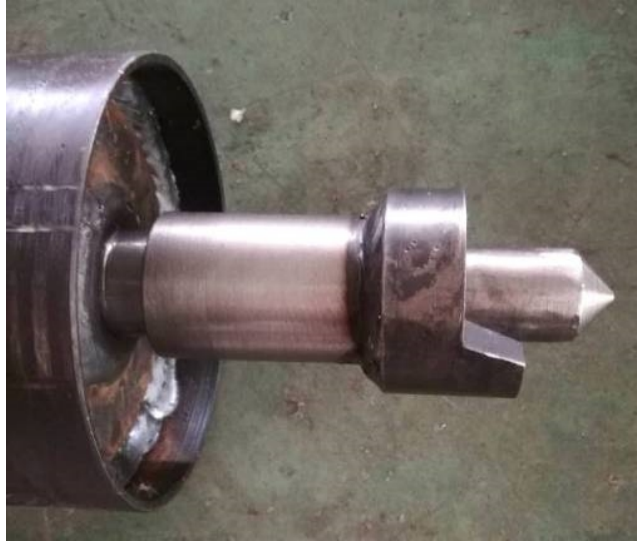

(a)male head butt joint structure

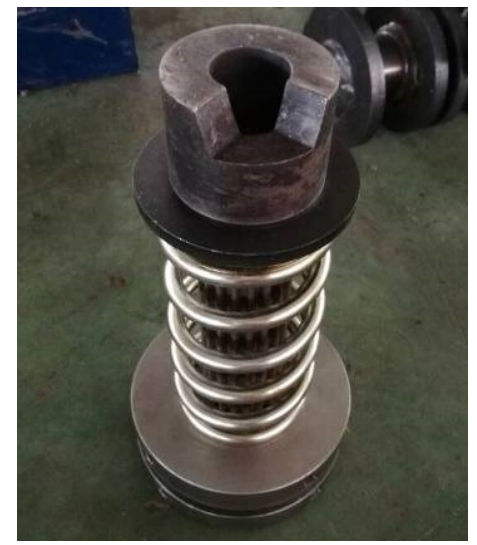

(b) female head butt joint structure

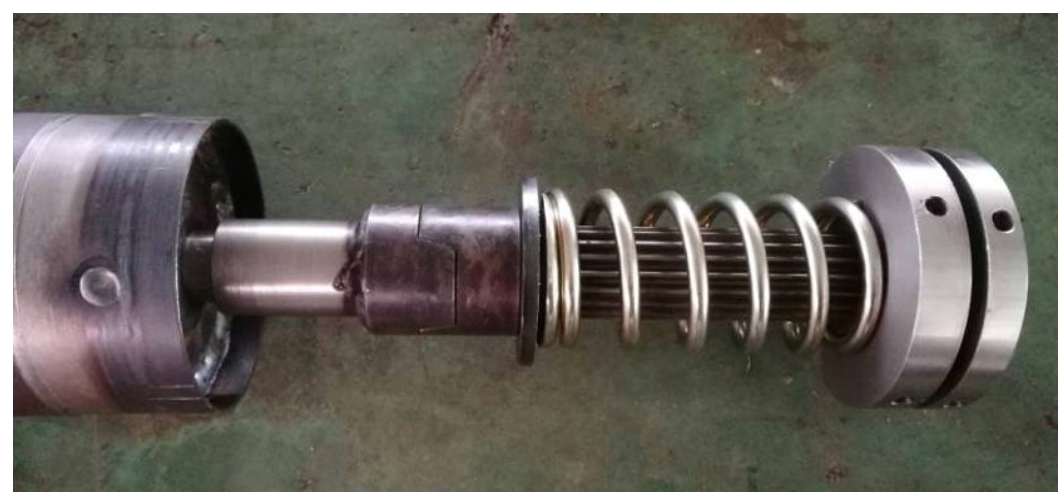

(c)docking effect

Fig 2.2 ground dragon butt joint structure

\section{the design of the pull type guide support frame}

Guide rail of the support frame is a kind of pull structure, if the middle of the guide rail and both sides are simple laid, they will need to fold, so there be guide rail joints, seamless docking accuracy requirement is very high, it will block the slider in the free sliding guide the joint, but due to the use of corn harvester environment and the limitations of agricultural machinery is not high precision and accuracy cannot be guaranteed, it will exist the problem in slide, and we can solve this problem very well through the special draw guide frame.

The pull-off rail frame is designed as three sections, in which the left and right sectio ns can be received into the middle section, the middle section is fixed on the support fram e of the cutting table, and the left and right sections can be drawn. The distribution of the snapping roll is symmetrical on the guide rail frame, in which the two snapping rolls are distributed on the left side of the drawing frame and the right end is also distributed with two sets of snapping rolls. The middle section rails are distributed with five snapping rolls, The leftmost and rightmost snapping roll combinations are welded to the two guide rails th at can be moved, which can drive the rail support frame together when sliding, Fig2.3 rail support frame (a) Figure for the cutting table rail support side view, (b) is a partial view o $\mathrm{f}$ the cutting table guide frame, and (c) is a connection view of the guide bracket and the snapping roll support plate 


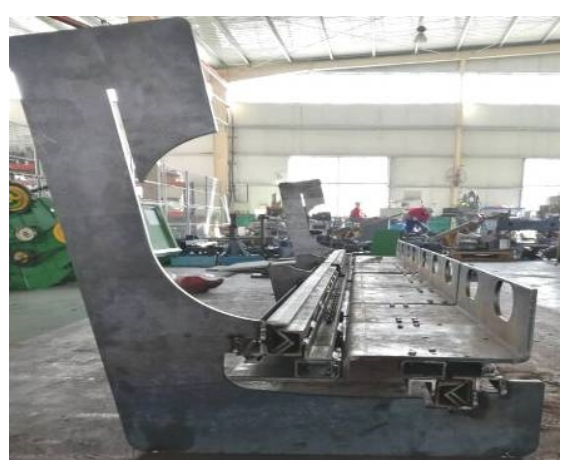

(a) cutting table side guide support frame

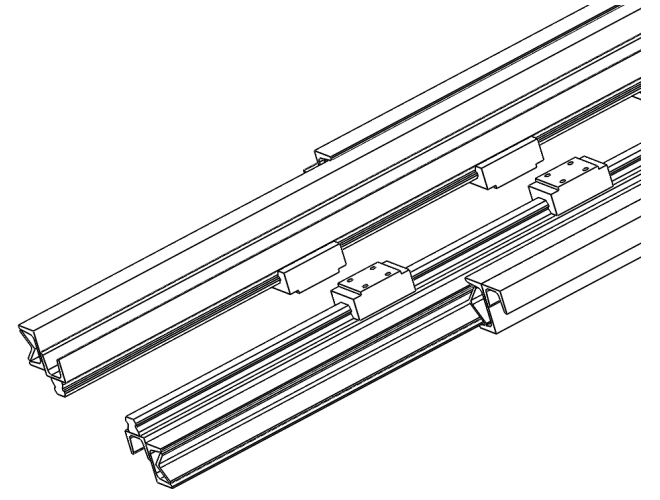

(b) pull type guide rail support part

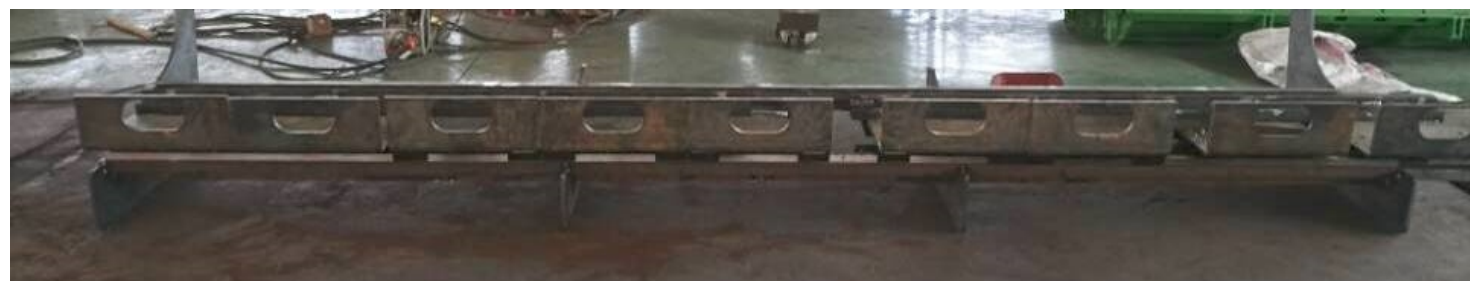

(c) connection diagram of the guide support frame and the stripper roller support plate

Fig 2.3 guide support frame

\section{Conclusions}

Based on the analysis of the corn header at home and abroad, this paper puts forward a new design ideas, according to the design requirements, design and design of the key parts of the header structure are described in detail, the structure design is that the entire header design is the most fundamental and important part, and the design results as follows in this paper, the general situation:

(1) According to the needs of the cutting platform, two design points of automatic alignment and folding are carried out. On the basis of the traditional cutting table design, the detailed design of the cutting platform structure is carried out, and the overall structural design scheme is determined;

(2) The main working principle of this design is briefly described;

\section{Acknowledgements}

This work was financially supported by the Shandong Province, the major project of science and technology (item number: 2015ZDZX10001) " the development and industrialization demonstration of intelligent corn combine harvester" .and Taishan industry leading talent project special funds. 


\section{References}

[1] Sharanakumar Hiregoudar. Artificial Neural Network for Assessment of grain losses for paddy combine harvester a novel approach ICLICC 2011[J]. Gandhigram,2011,2(160): 221-223.

[2] Shinners K J, Boettcher G C, Holfman D S, et al. Single-pass harvest of corn grain and stover: performance of three harvester con - figurations[J].Transactions of the ASABE,2009,52(1):51-60.

[3] Thomas Burnell Colhert. Iowa farmers and mechanical corn pickers[J].Agri-cultural History,2000,74(2):530-544.

[4] Yang Weiyu. Present development in China's maize harvesters and proposals[J].Agri-cultural Science and Technology and Equipment,2011(2):128.

[5] Manh A G, Rabatel G, Assemat L, Aldon M J. Weed Leaf Image Segmentation by Deformable Templates.Agric Eng Res,200180(2):139-146. 